\title{
Prospective Service Use and Health Care Costs of Medicaid Beneficiaries with Treatment-Resistant Depression
}

\author{
Mark Olfson, MD, MPH; Tony B. Amos, PharmD, MS; Carmela Benson, MS;
} Jacquelyn McRae, PharmD; and Steven C. Marcus, PhD

\begin{abstract}
BACKGROUND: Although the clinical and health economic characteristics of commercially insured adults with treatment-resistant depression (TRD) have been well characterized, little is known about TRD in the Medicaid population.
\end{abstract}

OBJECTIVE: To describe clinical and health economic characteristics of adult Medicaid beneficiaries with TRD.

METHODS: Retrospective longitudinal cohort analyses were performed with Truven Health MarketScan Medicaid Database (2008-2014), focusing on adults with major depressive disorder (MDD) following an index antidepressant prescription. TRD was operationally defined as starting a third treatment regimen after 2 adequate regimens of antidepressants or augmentation therapy within 12 months of an index antidepressant prescription. Among patients with and without TRD, percentages with inpatient admissions, emergency department visits, and outpatient visits (all cause, mental health related, and depression related) were determined. Logistic regression models were used to examine associations between TRD status and use of inpatient, outpatient, and emergency services. Separate analyses were performed for the first and second year after the index antidepressant prescription.

RESULTS: Approximately one quarter (25.9\%) of pharmacologically treated adults with MDD met criteria for TRD. In relation to MDD patients without TRD, patients with TRD were proportionately more likely to be older, male, and white. Compared with MDD patients without TRD, patients with TRD were also significantly more likely to receive inpatient care for any cause (31.0\% vs. $21.6 \% ; P<0.001)$, a mental health-related reason $(12.7 \%$ vs. $7.6 \%$; $P<0.001)$, or depression $(10.1 \%$ vs. $6.1 \%$; $P<0.001)$ during the first year following their index antidepressant prescription. Over the second follow-up year, patients with TRD continued to be more likely than patients without TRD to receive inpatient care for any reason $(26.7 \%$ vs. $19.5 \%$; $P<0.001$ ), a mental health-related reason (5.6\% vs. $2.7 \%$; $P<0.001$ ), and depression $(3.7 \%$ vs. $1.7 \% ; P<0.001)$. The mean health care costs of patients with TRD were also significantly higher than the costs of patients without TRD during the first year $(\$ 18,982[S D \pm \$ 35,276]$ vs. $\$ 11,642$ $[S D \pm \$ 29,203])$ and second year $(\$ 17,997[S D \pm \$ 34,146]$ vs. $\$ 10,325$ $[S D \pm \$ 28,224])$ following the index antidepressant prescription.

CONCLUSIONS: In the U.S. Medicaid program, adults with TRD have substantially and persistently higher health care costs than their counterparts who do not meet criteria for TRD. The service use and health care cost patterns of patients with TRD in the Medicaid program highlight challenges of developing interventions and care coordination strategies to meet their complex clinical needs.

J Manag Care Spec Pharm. 2018;24(3):226-36

Copyright $\odot 2018$, Academy of Managed Care Pharmacy. All rights reserved.

\section{What is already known about this subject}

Treatment-resistant depression (TRD) is major depressive disorder (MDD) in patients who have not responded adequately to at least 2 different antidepressants of adequate dose and duration. Commercially insured patients with TRD have health care costs that are roughly twice as high as those with treatment-responsive depression.

\section{What this study adds}

Within the U.S. Medicaid program, patients with MDD who have evidence of TRD have substantially higher health care costs than their counterparts who do not meet criteria for TRD.

Health care cost differences between depressed patients with TRD and those without TRD persist during the first year following the year in which TRD developed.

The persistence of health care cost differences over the year following development of TRD suggests that depression treatment resistance is often an enduring clinical characteristic.

M ajor depressive disorder (MDD) is one of the most common, disabling, and costly health conditions in the United States. ${ }^{1-3}$ Unfortunately, approximately half of depressed patients do not respond to an adequate trial of an antidepressant medication, and a significant proportion of these patients do not respond to multiple antidepressant treatments. ${ }^{4}$ Treatment-resistant depression (TRD), which is often defined as MDD that does not respond to at least 2 adequate treatments in an MDD episode, ${ }^{5}$ is common in clinical practice. Depending on the patient population and specific TRD definition, TRD has been reported to occur in 7\%-35\% of adults who are treated for depression. ${ }^{6-10}$

Adults with TRD bear a heavy burden of disease. According to recent literature reviews, adults with TRD as compared with those with treatment-responsive depression tend to have longer episodes of depression, more previous psychiatric hospital admissions, higher symptom severity, and a greater risk of comorbid anxiety disorders. ${ }^{11,12}$ The prevalence of suicidal ideation in TRD (15\%) is over twice as high as its prevalence in treatment-responsive depression $(6 \%) \cdot{ }^{13}$ In addition, adults with TRD report significantly poorer quality of life and an earlier age of onset of depression than patients with treatmentresponsive depression. ${ }^{13,14}$ 
Because of their complex health care needs, patients with TRD place heavy demands on health care resources. According to 1 analysis, for example, the costs of TRD patients for office visits to psychiatrists and for emergency department visits were each over 5 times greater than their respective costs for patients with non-TRD depression. ${ }^{8}$ With 1 exception, ${ }^{15}$ the overall health care costs of TRD have been reported to be nearly twice or more than twice as high as those with treatmentresponsive depression. ${ }^{6-8,16,17}$ Our understanding of the clinical characteristics and economic implications of TRD has been built up from clinical data and from claims records of commercially insured patients. ${ }^{6-8,11,14,17,18}$ Much less is known about the demographic and clinical characteristics, predictors, and health care economic burden of TRD among adult Medicaid beneficiaries. Because Medicaid is the largest single source of financing for mental health services in the United States, ${ }^{19}$ Medicaid patients with TRD represent a large, impaired, and expensive-to-manage, but poorly characterized, patient group.

In light of recent advances in the treatment of TRD and the recent expansion of Medicaid under the Affordable Care Act, ${ }^{20}$ it is important to increase our understanding of readily identifiable demographic and clinical risk factors for TRD and its health care economic burden in the Medicaid population. In an effort to help fill these gaps in our knowledge of TRD, we identified predictors and health care cost consequences of TRD among nonelderly Medicaid beneficiaries. To assess the persistence of service demands, we also compared patients with and without TRD with respect to service use and health care costs during the first and second years following initiation of treatment for a depressive episode.

\section{Methods}

\section{Data Source}

The analyses used Truven Health Analytics MarketScan Medicaid Database between the dates of January 1, 2008, and July 31, 2014. This database includes person-specific demographic, enrollment, expenditure, and clinical utilization information from approximately 8-12 million Medicaid enrollees within each year from multiple states. The clinical utilization data includes inpatient, emergency department, outpatient, and prescription data. Because the data were stripped of personal identifiers, this project was exempted from human subjects review by the institutional review board of the New York State Psychiatric Institute.

\section{Sample Selection}

This was an observational study with a retrospective cohort design that used administrative claims data. The initial inclusion criteria captured Medicaid adult patients who were aged 18-64 years and had continuous pharmacy benefit and mental health/substance use coverage for 12 months before and 24 months after starting an antidepressant prescription that occurred after $\geq 6$ months without an antidepressant prescription claim. We refer to this antidepressant prescription, which marks the beginning of the depression treatment episode used to define either TRD or non-TRD, as the index antidepressant prescription. In order to help limit the cohort to patients receiving antidepressants for the treatment of depression, patients were required to have $\geq 1$ diagnosis for depression (International Classification of Diseases, Ninth Revision, Clinical Modification [ICD-9-CM] codes 296.2, 296.3, 300.4, 311, 309.0, and 309.1) within 30 days before or after the index antidepressant prescription fill. In addition, patients were required to have $\geq 1$ diagnosis of MDD (ICD-9-CM codes 296.2 and 296.3) during the 12 months before or after the index antidepressant fill. Patients with $\geq 1$ claim for schizophrenia (ICD-9-CM code 295.xx), psychosis (298.xx), bipolar disorder/manic depression (296.0x-296.1x, 296.4x-296.8x), or dementia (290.xx and 294.1x) were excluded from the cohort. Patients with Medicare coverage during the 12 months before or 24 months after the index antidepressant fill were also excluded from the cohort (Appendix A, available in online article).

\section{Study Design and Study Period}

This analysis characterized patients with MDD during 3 different time periods in relation to the initiation of their index treatment episode: (1) a 12-month baseline period before antidepressant treatment initiation, (2) a 12-month period following antidepressant initiation, and (3) a 12-month extension period following period 2. In the first period, demographic and clinical characteristics, described in the following sections, were collected during the 12-month baseline period immediately before the date of the index antidepressant prescription.

This analysis focused on identifying characteristics during the 12-month period before the depression treatment episode that predict subsequent development of TRD. The second 12-month period following antidepressant initiation was the incidence observation used to identify patients with MDD who met the criteria for TRD. In this period, we compared the service utilization pattern and direct health care costs of patients with and without TRD during the 1-year period following initiation of their depression treatment episodes.

The third period describes short-term downstream service utilization and health care cost consequences of developing TRD during the following year (i.e., 13-24 months following the index antidepressant prescription fill).

These analyses were performed with patients who were aged 18-64 years and had continuous pharmacy and medical coverage for 12 months before and 24 months after an index antidepressant prescription that occurred after $\geq 6$ months without an antidepressant prescription claim. Within 30 days before or after the index antidepressant prescription fill, patients were required to have $\geq 1$ diagnosis for depression (ICD-9-CM codes 
TABLE 1 Background and Clinical Characteristics of Medicaid Beneficiaries Treated for Depression with and Without TRD

Patient Characteristics (\%)

Patients

with TRD

$(\mathrm{n}=1,503)$

Age, years

\begin{tabular}{l|l}
\hline $18-34$ & \\
\hline $35-44$ & \\
\hline $45-54$ & 26 \\
\hline $55-64$ & \\
\hline
\end{tabular}

Sex

Female

Male

Race/ethnicity

\begin{tabular}{l|l}
\hline White & 65.9 \\
\hline Black & 26.1 \\
\hline Hispanic & \\
\hline Other &
\end{tabular}

Health plan type

Indemnity

$\mathrm{HMO}$

POS

Elixhauser comorbidity score

\begin{tabular}{l|l}
\hline 0 & 10.8 \\
\hline 1 & 35.3 \\
\hline 2 & 36.5 \\
\hline $3+$ & 27.4 \\
\hline Outpatient mental health services
\end{tabular}

Outpatient mental health services

Substance use

Anxiety

Other mental health

Any mental health emergency services

Any mental health inpatient services

Selected medical comorbidities

\begin{tabular}{|c|c|c|c|c|c|}
\hline Diabetes mellitus & 13.2 & 8.5 & $1.64 \quad(1.36-1.96)$ & 1.37 & $(1.13-1.66)$ \\
\hline Congestive heart failure & 1.8 & 1.3 & $(0.87-2.20)$ & 1.08 & $(0.67-1.73)$ \\
\hline Ischemic heart disease & 3.7 & 2.8 & $(0.98-1.88)$ & 0.92 & $(0.66-1.29)$ \\
\hline Chronic pulmonary disease & 14.6 & 11.1 & $(1.15-1.62)$ & 1.23 & $(1.03-1.46)$ \\
\hline
\end{tabular}

a Results from separate logistic regressions, one for each patient characteristic, with TRD as the dependent variable.

${ }^{b}$ Adjusted for age, sex, racelethnicity, health plan type, and year.

$C I=$ confidence interval; $H M O=$ health maintenance organization; $O R=$ odds ratio; $P O S=$ point of service; $T R D=$ treatment-resistant depression

296.2, 296.3, 300.4, 311, 309.0, and 309.1), along with meeting the other previously described eligibility criteria.

\section{Treatment-Resistant Depression}

Study patients were classified as TRD or non-TRD using a claims-based algorithm for identifying TRD. We used the concept that an antidepressant treatment trial required at least 6 weeks of antidepressant availability at an adequate dose, which was adapted from the Massachusetts General Hospital Antidepressant Treatment Response Questionnaire. ${ }^{21}$ TRD was defined as initiating a third regimen of depression treatment after 2 different regimens of antidepressants or augmentation therapy at adequate dose and duration in the 12 months after the index antidepressant prescription. Treatment regimens included use of the same antidepressant or augmentation medication (anticonvulsant, antipsychotic, lithium, psychostimulant, or thyroid hormone) at adequate dose for at least 6 weeks without gaps of longer than 14 days. Adequate dose was defined by the recommended minimal dosage in the American Psychiatric Association practice guidelines or in the product package inserts approved by the U.S. Food and Drug Administration. ${ }^{22} \mathrm{~A}$ list of adequate antidepressant doses and augmentation therapies appears in Appendix B (available in online article). 
TABLE 2 Service Use Outcomes of Medicaid Beneficiaries Treated for Depression with and Without TRD During Months 1 to 12

\begin{tabular}{|c|c|c|c|c|}
\hline Service Types & $\begin{array}{c}\text { Patients } \\
\text { with TRD } \\
(\mathrm{n}=1,503)\end{array}$ & $\begin{array}{c}\text { Patients } \\
\text { Without TRD } \\
(\mathrm{n}=4,298)\end{array}$ & $\begin{array}{l}\text { Unadjusted OR/ } / \beta^{a} \\
(95 \% \text { CI })\end{array}$ & $\begin{array}{c}\text { Adjusted OR/ } \beta \text { a,b } \\
(95 \% \mathrm{CI})\end{array}$ \\
\hline Any inpatient admission, \% & & & OR & OR \\
\hline All cause & 31.0 & 21.6 & $1.63(1.43-1.86)$ & $1.58 \quad(1.38-1.81)$ \\
\hline Mental health related & 12.7 & 7.6 & $1.77 \quad(1.47-2.14)$ & $1.97 \quad(1.62-2.39)$ \\
\hline Depression related & 10.1 & 6.1 & $1.73 \quad(1.41-2.14)$ & $1.95 \quad(1.58-2.42)$ \\
\hline Number of inpatient days, median & & & $\beta$ & $\beta$ \\
\hline All cause & 5.0 & 4.0 & $1.81 \quad(0.09-3.53)$ & $1.94 \quad(0.22-3.67)$ \\
\hline Mental health related & 6.0 & 5.0 & $2.56 \quad(0.87-4.25)$ & $2.96 \quad(1.27-4.65)$ \\
\hline Depression related & 6.0 & 5.0 & $1.83 \quad(0.14-3.53)$ & $2.17 \quad(0.48-3.87)$ \\
\hline Any ED visit (\%) & & & $\mathrm{OR}$ & OR \\
\hline All cause & 50.0 & 44.0 & $(1.04-1.32)$ & $1.28 \quad(1.12-1.45)$ \\
\hline Mental health related & 28.1 & 5.8 & $1.53 \quad(1.23-1.91)$ & $1.65 \quad(1.32-2.07)$ \\
\hline Depression related & 17.6 & 2.4 & $1.33 \quad(0.94-1.88)$ & $1.56 \quad(1.10-2.23)$ \\
\hline Number of ED visit days, median & & & $\beta$ & $\beta$ \\
\hline All cause & 2.0 & 2.0 & $0.90 \quad(0.28-1.51)$ & $0.99 \quad(0.36-1.62)$ \\
\hline Mental health related & 1.0 & 1.0 & $0.07 \quad(-0.11-0.25)$ & $0.08 \quad(-0.11-0.26)$ \\
\hline Depression related & 1.0 & 1.0 & $0.00 \quad(-0.15-0.16)$ & $0.02 \quad(-0.15-0.19)$ \\
\hline Any outpatient visit (\%) & & & OR & OR \\
\hline All cause & 100.0 & 100.0 & $\mathrm{c}$ & $\mathrm{c}$ \\
\hline Mental health related & 97.3 & 96.1 & $1.48 \quad(1.04-2.10)$ & $1.57 \quad(1.10-2.25)$ \\
\hline Depression related & 93.9 & 92.5 & $1.26 \quad(0.99-1.60)$ & $1.29 \quad(1.01-1.65)$ \\
\hline Outpatient visit days, median & & & $\beta$ & $\beta$ \\
\hline All cause & 31.0 & 20.5 & $11.69 \quad(9.45-13.92)$ & $(8.02-12.46)$ \\
\hline Mental health related & 12.0 & 8.0 & $6.44 \quad(4.67-8.20)$ & $(4.68-8.22)$ \\
\hline Depression related & 9.0 & 5.0 & $4.47 \quad(3.16-5.78)$ & $4.17 \quad(2.85-5.49)$ \\
\hline \multicolumn{5}{|c|}{$\begin{array}{l}\text { aOR results are from a series of logistic regressions with TRD status as independent variable of interest and each service type as the dependent variable. Beta coefficients } \\
\text { are from a series of quantile regressions with TRD status as the independent variable of interest and median number days of each service type as the dependent variable. } \\
\text { bAdjusted for age, sex, racelethnicity, year, and health plan type. } \\
\text { cNot calculable because all patients had outcome of interest. } \\
\beta=\text { beta coefficient; } C I=\text { confidence interval; ED = emergency department; OR=odds ratio; TRD = treatment-resistant depression. }\end{array}$} \\
\hline
\end{tabular}

\section{Independent and Dependent Variables}

In the analysis of the 12-month baseline period, patient background characteristics were the independent variables, and TRD served as the dependent variable (Table 1). These background characteristics included age group (aged 18-34, 35-44, 45-54, and 55-64 years); sex; racelethnicity (white, black, Hispanic, and other); and health plan type (indemnity, health maintenance organization [HMO], and preferred provider organization). Clinical characteristics were based on service claims during the 12 months before the index antidepressant fill. They included the Elixhauser comorbidity score to measure the number of treated comorbid medical conditions and outpatient diagnoses of substance use disorder (ICD-9-CM codes 291-292 and 303-305) 23; anxiety disorders (300.0, 300.2, 300.3, 304, and 308.3); other mental disorders (290-319, not already included); diabetes mellitus (250.00250.33 and 250.40-250.93); congestive heart failure (398.91,
$402.01,402.11,402.91,404.01,404.11,404.91$, and 428.0428.9); ischemic heart disease (410-414); and chronic pulmonary disease (490-492.8, 493.00-493.92, 494-494.1, 495.0505, and 506.4). Patients were also classified with respect to receiving inpatient and emergency department visits with any listed mental disorder diagnosis during the year before the index antidepressant prescription.

In the analysis of the first 12-month follow-up period, TRD was the key independent variable, and service use variables (Table 2) and direct cost variables (Table 3) were the dependent variables. A similar analytic structure was used for service variables (Table 4) and direct cost variables (Table 5) measured during the 12-month extension follow-up period. For the service use analyses, dependent variables included the presence of $\geq 1$ inpatient admission or emergency department and outpatient visit during the first and second 12-month follow-up periods. For each type of service, separate variables measured all-cause, 
TABLE 3 Mean Health Care Costs of Medicaid Beneficiaries Treated for Depression with and Without TRD During Months 1 to 12

\begin{tabular}{|c|c|c|c|c|}
\hline Cost Categories & $\begin{array}{c}\text { Patients with TRD } \\
\text { Mean (SD) } \\
n=1,503\end{array}$ & $\begin{array}{c}\text { Patients Without TRD } \\
\text { Mean (SD) } \\
\mathbf{n}=4,298\end{array}$ & $\begin{array}{l}\text { Unadjusted } \beta^{a} \\
\quad(95 \% \mathrm{CI})\end{array}$ & $\begin{array}{c}\text { Adjusted } \beta \mathrm{a}, \mathrm{b} \\
(95 \% \mathrm{CI})\end{array}$ \\
\hline \multicolumn{5}{|c|}{ Total health care costs, $\$$} \\
\hline Total & $18,982(35,276)$ & $11,642(29,203)$ & $6,504(4,862-8,146)$ & $6,969 \quad(6,087-7,851)$ \\
\hline Mental health related & $5,703 \quad(9,771)$ & $2,999 \quad(7,171)$ & $2,348 \quad(1,911-2,784)$ & $2,555 \quad(2,121-2,990)$ \\
\hline Depression related & $3,112 \quad(5,760)$ & $1,910 \quad(4,632)$ & $1,065 \quad(796-1,335)$ & $1,083 \quad(895-1,270)$ \\
\hline \multicolumn{5}{|c|}{ Prescription pharmacy costs, $\$$} \\
\hline Total & $4,972 \quad(8,096)$ & $2,193 \quad(5,211)$ & $2,352 \quad(1,991-2,712)$ & $2,305(2,083-2,528)$ \\
\hline Psychotropic & $1,573 \quad(2,440)$ & $332 \quad(1,112)$ & $989 \quad(890-1,087)$ & $970 \quad(866-1,074)$ \\
\hline Antidepressants & $644 \quad(989)$ & $267 \quad(535)$ & $(274-360)$ & $(239-321)$ \\
\hline \multicolumn{5}{|l|}{ Inpatient care costs, $\$$} \\
\hline Total & $5,311(27,582)$ & $3,625(24,713)$ & $1,539 \quad(193-2,885)$ & $(787-3,458)$ \\
\hline Mental health related & $906 \quad(4,801)$ & $397 \quad(2,427)$ & $(230-631)$ & $(293-740)$ \\
\hline Depression related & $645 \quad(3,482)$ & $315 \quad(2,132)$ & $(136-430)$ & $(192-509)$ \\
\hline \multicolumn{5}{|c|}{ Emergency department costs, \$ } \\
\hline Total & $568 \quad(1,952)$ & $333 \quad(1,028)$ & $(119-294)$ & $(128-286)$ \\
\hline Mental health related & $25 \quad(176)$ & $15 \quad(120)$ & $(2-17)$ & $(2-16)$ \\
\hline Depression related & (49) & (39) & $(-1-4)$ & $(0-5)$ \\
\hline \multicolumn{5}{|l|}{ Outpatient care costs, \$ } \\
\hline Total & $7,322(11,023)$ & $5,013 \quad(9,269)$ & $2,084 \quad(1,557-2,610)$ & $2,026 \quad(1,537-2,515)$ \\
\hline Mental health related & $2,717 \quad(6,183)$ & $1,990 \quad(5,917)$ & $665 \quad(362-968)$ & $829 \quad(552-1,106)$ \\
\hline Depression related & $1,655 \quad(3,704)$ & $1,223 \quad(3,849)$ & $(201-589)$ & $(240-575)$ \\
\hline \multicolumn{5}{|c|}{ Other medical care costs, $\$$} \\
\hline Total & $810 \quad(4,805)$ & $478 \quad(2,880)$ & $(85-501)$ & $(46-372)$ \\
\hline Mental health related & $481 \quad(3,792)$ & $266 \quad(2,259)$ & $(21-354)$ & $(-2-283)$ \\
\hline Depression related & $162 \quad(1,385)$ & $101 \quad(757)$ & $(-10-118)$ & $(-12-87)$ \\
\hline
\end{tabular}

mental health-related (290-319), and depression-related (296.2, 296.3, 300.4, 311, 309.0, and 309.1) episodes. Among patients with service episodes, the numbers of inpatient days, emergency department visit days, and outpatient visit days, respectively, were also considered during the 2 follow-up periods. These variables were also considered as all-cause, mental health-related, and depression-related groups on the basis of any listed diagnoses.

Total health care costs were defined as gross payments to a provider after applying pricing guidelines, such as fee schedules and discounts, and before applying deductibles, copayments, and coordination of benefits policies. Total health care costs were defined for each study patient during the first and second follow-up periods. Following the classification for services, costs were partitioned by service into inpatient, emergency, and outpatient and by clinical focus into total, mental health related, and depression related on the basis of any listed ICD-9-CM codes. In addition, separate categories were created for prescription pharmacy costs and a residual group of other medical care costs.

\section{Statistical Analysis}

Baseline demographic and clinical service use characteristics of patients with and without TRD were first compared using unadjusted and adjusted (age, sex, race, health plan type, and study year) logistic models. Among patients with and without TRD, we then determined the percentage of each categorical service use outcome and, among those of service use, the median number of service days. Logistic regression models were used to examine associations between TRD status during the first follow-up period, and the categorical service use variables and quantile regressions were used for the median service day outcomes in each follow-up period.

Mean health care costs and associated standard deviations (SDs) within each cost category were then calculated separately for patients with and without TRD. We conducted unadjusted and adjusted regression models using Stata twopm (StataCorp, College Station, TX) to examine the effect of TRD on treatment costs. ${ }^{24}$ Because some patients had no treatment costs, we used 2-part models for all analyses, which are commonly used when a large proportion of the population has no costs, and those with costs have a skewed distribution of costs. ${ }^{25}$ 
TABLE 4 Service Use Outcomes of Cohort Medicaid Beneficiaries Treated for Depression with and Without TRD During Months 13 to 24

\begin{tabular}{|c|c|c|c|c|c|}
\hline Service Types & $\begin{array}{c}\text { Patients } \\
\text { with TRD } \\
(\mathrm{n}=1,503)\end{array}$ & $\begin{array}{c}\text { Patients } \\
\text { Without TRD } \\
(\mathrm{n}=4,298)\end{array}$ & $\begin{array}{c}\text { Unadjusted OR/ } / \beta^{\mathrm{a}} \\
(95 \% \mathrm{CI})\end{array}$ & \multicolumn{2}{|c|}{$\begin{array}{c}\text { Adjusted OR/ } / \beta a, b \\
(95 \% \mathrm{CI})\end{array}$} \\
\hline Any inpatient admission, $\%$ & & & OR & & OR \\
\hline All cause & 26.7 & 19.5 & $(1.31-1.72)$ & 1.42 & $(1.23-1.63)$ \\
\hline Mental health related & 5.6 & 2.7 & $2.15 \quad(1.61-2.87)$ & 2.04 & $(1.52-2.73)$ \\
\hline Depression related & 3.7 & 1.7 & $2.18 \quad(1.53-3.10)$ & 2.13 & $(1.49-3.05)$ \\
\hline Number of inpatient days, median & & & $\beta$ & \multicolumn{2}{|r|}{$\beta$} \\
\hline All cause & 4.0 & 3.0 & $3.58 \quad(0.71-6.45)$ & 3.59 & $(0.64-6.53)$ \\
\hline Mental health related & 5.0 & 5.0 & $2.58(-2.50-7.66)$ & 3.39 & $(-2.07-8.84)$ \\
\hline Depression related & 4.0 & 4.0 & $-0.42 \quad(-2.97-2.13)$ & -0.81 & $(-3.53-1.91)$ \\
\hline Any ED visit, \% & & & OR & \multicolumn{2}{|r|}{ OR } \\
\hline All cause & 47.7 & 44.8 & $(1.00-1.27)$ & 1.19 & $(1.05-1.35)$ \\
\hline Mental health related & 5.7 & 4.3 & $(1.02-1.73)$ & 1.32 & $(1.05-1.35)$ \\
\hline Depression related & 1.9 & 1.1 & $1.78 \quad(1.12-2.84)$ & 1.89 & $(1.18-3.05)$ \\
\hline Number of ED visit days, median & & & $\beta$ & \multicolumn{2}{|r|}{$\beta$} \\
\hline All cause & 2.0 & 2.0 & $1.11 \quad(0.45-1.77)$ & 1.17 & $(0.50-1.84)$ \\
\hline Mental health related & 1.0 & 1.0 & $0.04(-0.15-0.23)$ & 0.03 & $(-0.17-0.23)$ \\
\hline Depression related & 1.0 & 1.0 & $0.11 \quad(-0.07-0.29)$ & 0.11 & $(-0.08-0.30)$ \\
\hline Any outpatient visit, $\%$ & & & OR & \multicolumn{2}{|c|}{ OR } \\
\hline All cause & 97.0 & 94.7 & $(1.30-2.50)$ & 1.80 & $(1.29-2.50)$ \\
\hline Mental health related & 79.0 & 61.2 & $(2.08-2.75)$ & 2.26 & $(1.96-2.60)$ \\
\hline Depression related & 65.9 & 47.1 & $2.16 \quad(1.91-2.45)$ & 2.05 & $(1.81-2.32)$ \\
\hline Outpatient visit days, median & & & $\beta$ & \multicolumn{2}{|r|}{$\beta$} \\
\hline All cause & 22.0 & 14.0 & $10.17 \quad(7.61-12.72)$ & 8.01 & $(5.47-10.54)$ \\
\hline Mental health related & 8.0 & 5.0 & $(1.20-5.74)$ & 3.46 & $(1.18-5.75)$ \\
\hline Depression related & 6.0 & 4.0 & $(0.90-4.49)$ & 2.39 & $(0.59-4.19)$ \\
\hline
\end{tabular}

The first part of the model used a logistic regression to predict any cost during the study period, while the second part used a generalized linear model with a gamma distribution and log link to predict costs among those with non-zero costs during this period. The predicted costs for each patient were derived by multiplying predicted costs from each part of the model. For ease of interpretation, we present the predictive margins to quantify the average cost difference between TRD and non-TRD groups. $P$ values for this difference were obtained using a nonparametric bootstrap with 500 iterations. A sensitivity analysis was performed by comparing direct health care costs with further adjustment for medical comorbidity burden with the Elixhauser comorbidity score.

\section{Results}

\section{Background and Clinical Characteristics of TRD}

Of the 5,801 patients who met study eligibility criteria, approximately one quarter $(25.9 \% ; n=1,503)$ of the pharmacologically treated patients with MDD met criteria for TRD during the first 12 months after their index antidepressant prescription fills. Among the study sample, the crude or unadjusted odds of TRD were 1.24 times higher for males than females. As compared with depressed patients without TRD, those with TRD were also proportionately more likely to be older, white, and in indemnity rather than HMO health plans. During the year before the index antidepressant prescription, patients who met criteria for TRD were also more likely than patients without TRD to have been diagnosed with a substance use disorder, a chronic pulmonary disease, and diabetes. The TRD cohort was also more likely than the non-TRD cohort to have received inpatient mental health treatment and to have an elevated Elixhauser comorbidity score during the year before the index pharmacological regimen. After controlling for background characteristics, the associations of age, race, health plan type, diabetes, comorbidity, and inpatient mental health services during the pre-baseline period with TRD status remained significant (Table 1). 
TABLE 5 Mean Health Care Costs for Medicaid Beneficiaries Treated for Depression with and Without TRD During Months 13 to 24

\begin{tabular}{|c|c|c|c|c|}
\hline Cost Categories & $\begin{array}{c}\text { Patients with TRD } \\
\text { Mean (SD) } \\
\mathrm{n}=1,503\end{array}$ & $\begin{array}{c}\text { Patients Without TRD } \\
\text { Mean (SD) } \\
\mathbf{n}=4,298\end{array}$ & $\begin{array}{l}\text { Unadjusted } \beta a \\
(95 \% \mathrm{CI})\end{array}$ & $\begin{array}{c}\text { Adjusted } \beta \mathrm{a}, \mathrm{b} \\
(95 \% \mathrm{CI})\end{array}$ \\
\hline \multicolumn{5}{|c|}{ Total health care costs, $\$$} \\
\hline Total & $17,997 \quad(34,146)$ & $10,325 \quad(28,224)$ & $6,749 \quad(5,268-8,230)$ & $5,923 \quad(4,409-7,437)$ \\
\hline Mental health related & $4,122 \quad(8,657)$ & $1,869 \quad(6,643)$ & $1,957 \quad(1,586-2,327)$ & $2,015 \quad(1,607-2,423)$ \\
\hline Depression related & $1,969 \quad(4,203)$ & $(3,314)$ & $899 \quad(725-1,072)$ & $760 \quad(595-925)$ \\
\hline \multicolumn{5}{|c|}{ Prescription pharmacy costs, $\$$} \\
\hline Total & $(9,529)$ & $(6,881)$ & $2,330 \quad(1,883-2,777)$ & $2,031 \quad(1,673-2,389)$ \\
\hline Psychotropic & $1,475 \quad(2,941)$ & $(1,311)$ & $899 \quad(780-1,018)$ & $829 \quad(710-949)$ \\
\hline Antidepressants & $(1,017)$ & $(574)$ & $(241-326)$ & $(191-276)$ \\
\hline \multicolumn{5}{|l|}{ Inpatient care costs, $\$$} \\
\hline Total & $5,637 \quad(27,493)$ & $3,293 \quad(22,547)$ & $(855-3,288)$ & $(411-3,113)$ \\
\hline Mental health related & $391 \quad(4,125)$ & $172 \quad(1,890)$ & $(10-359)$ & $(16-295)$ \\
\hline Depression related & $(1,511)$ & $(1,545)$ & $(10-155)$ & $(-5-144)$ \\
\hline \multicolumn{5}{|c|}{ Emergency department costs, \$ } \\
\hline Total & $(1,869)$ & $(1,247)$ & $(50-232)$ & $(37-201)$ \\
\hline Mental health related & (97) & $(101)$ & $(-2-9)$ & $(-2-8)$ \\
\hline Depression related & (34) & $(31)$ & $(-1-2)$ & $(-1-3)$ \\
\hline \multicolumn{5}{|l|}{ Outpatient care costs, \$ } \\
\hline Total & $6,126 \quad(10,907)$ & $(9,075)$ & $1,923 \quad(1,436-2,409)$ & $1,565 \quad(1,115-2,016)$ \\
\hline Mental health related & $1,835 \quad(5,389)$ & $(5,120)$ & $653 \quad(412-894)$ & $672 \quad(445-900)$ \\
\hline Depression related & $(3,169)$ & $(2,674)$ & $(291-566)$ & $(235-473)$ \\
\hline \multicolumn{5}{|c|}{ Other medical care costs, $\$$} \\
\hline Total & $(4,214)$ & $(3,137)$ & $(71-449)$ & $(110-400)$ \\
\hline Mental health related & $(3,252)$ & $(2,649)$ & $(19-312)$ & $(44-280)$ \\
\hline Depression related & $(1,148)$ & $(586)$ & $(41-139)$ & $(35-141)$ \\
\hline
\end{tabular}

\section{Service Use Outcomes During Post-index Months 1 to 12}

During the first follow-up year, patients who met criteria for TRD were significantly more likely than patients without TRD to receive inpatient care for any reason (31.0\% vs. $21.6 \%)$, as well as for a mental health condition $(12.7 \%$ vs. $7.6 \%)$ and for depression (10.1\% vs. $6.1 \%$; all $P$ values $<0.001$; Table 2$)$. Among those who received inpatient mental health care, the median length of stay was longer for patients with TRD than for those without TRD. These relationships remained significant after controlling for background patient characteristics (Table 2). During the first 12 months after the index antidepressant medication prescription, all-cause and mental health-related emergency department visits were also significantly more common among patients with TRD than among those without TRD in the unadjusted and adjusted analyses. Among patients with mental health-related emergency department visits, patients with TRD, compared with those without TRD, also had a significantly larger median number of such visit days. All patients with and without TRD had outpatient visits during the first follow-up year. However, compared with patients without TRD, patients with TRD had a significantly larger median number of outpatient visits (Table 2).

Health Care Cost Outcomes During Post-index Months 1 to 12 Consistent with the service use patterns, mean total health care costs were significantly higher for patients with TRD $(\$ 18,982[S D \pm \$ 35,276])$ than for those without TRD $(\$ 11,642$ [SD $\pm \$ 29,203])$ during the first year after their index antidepressant prescriptions. Cost differences between the patient groups remained significant after controlling for background patient characteristics (beta coefficient $[\beta]=\$ 6,969,95 \%$ confidence interval $[\mathrm{CI}]=\$ 6,087-\$ 7,851$; Table 3 ) and in a sensitivity analysis that also adjusted for the Elixhauser score $(\beta=\$ 6,765$, $95 \% \mathrm{CI}=\$ 5,864-\$ 7,666)$.

Similar group differences in mean costs were observed for outpatient care and for total, psychotropic, and antidepressant pharmacy costs during the first year of follow-up. Mean mental health-related and depression-related inpatient care costs, as well as total emergency department costs, were also 
significantly higher for patients with TRD than for patients without TRD during this period (Table 3).

\section{Service Use Outcomes During Post-index Months 13 to 24}

Over the second 12-month period of follow-up, several of the group differences in service use were maintained. Specifically, patients with TRD continued to be significantly more likely than patients without TRD to receive inpatient care for any cause $(26.7 \%$ vs. $19.5 \%$; $P<0.001)$, as well as for mental healthrelated $(5.6 \%$ vs. $2.7 \% ; P<0.001)$ and depression-related diagnoses (3.7\% vs. 1.7\%; $P<0.001$; Table 4). Among patients with any emergency department visits and within each of the 3 categories of outpatient visits, patients with TRD also continued to have a significantly higher median number of days of service use than patients without TRD. Although not evident in the first follow-up year because of ceiling effects, patients with TRD were also significantly more likely than patients without TRD to have any outpatient visit, as well as mental health-related and depression-related outpatient visits, during the second follow-up year (Table 4).

\section{Health Care Cost Outcomes During Post-index Months 13 to 24}

Several of the group differences in health care costs were also maintained during the second year of follow-up. Unadjusted mean total health care costs were significantly higher for patients with TRD $(\$ 17,997$ [SD $\pm \$ 34,146])$ than without TRD $(\$ 10,325[S D \pm \$ 28,224])$ during this period and remained significantly higher after adjustment for age, sex, race/ethnicity, year, and health plan type $(\beta=\$ 5,923,95 \% \mathrm{CI}=\$ 4,409-\$ 7,437$; Table 5). In a sensitivity analysis that also adjusted for the Elixhauser score, the mean total health care cost difference was little changed $(\beta=\$ 5,898,95 \% \mathrm{CI}=\$ 4,315-\$ 7,482)$. In relation to patients without TRD, patients with TRD also continued to have significantly higher mean mental health-related and depression-related health care costs during the second year, as well as higher total, psychotropic, and antidepressant prescription pharmacy costs. In addition, the mean total outpatient, mental health-related, and depression-related health care costs of patients with TRD were significantly higher than those of patients without TRD during the second 12 months of followup (Table 5).

\section{Discussion}

Within the adult nonelderly Medicaid population, TRD is a common condition that is associated with persistently elevated health care costs. Consistent with research based on commercially insured patients, ${ }^{6,8,16,17}$ approximately one quarter of adult depressed patients in the Medicaid program met the TRD criteria over the first year of a depression treatment episode. During this period, their overall health care costs were approximately two-thirds higher than the costs of depressed patients who did not meet the TRD criteria. This cost difference, which was distributed across inpatient, outpatient, emergency, and pharmacy services, persisted during the second year of follow-up.

The clinical profile of patients with TRD in the Medicaid program, which included disproportionately older adults and those with general medical comorbid disorders, is consistent with clinical research on the course of depressive disorders. In clinical studies, older patient age and medical comorbidities have been linked to poor outcomes of depression. ${ }^{26,27}$ In practice, these patients are more likely to receive treatment in general medical than in specialty mental health settings. ${ }^{28}$ In view of the increased risk for TRD in these patients, dedicated efforts may be required to strengthen care coordination to increase their access to specialized mental health services. With greater emphasis on integration of mental and physical health services and transitions toward behavioral health homes, ${ }^{29}$ there are also new opportunities in several health care systems for providing specialized mental health treatment of depression to older adult patients with medical comorbidities. Models that coordinate the care of depression and chronic medical illnesses have been shown to improve clinical outcomes of both conditions. ${ }^{30}$

In this Medicaid-insured sample with TRD, outpatient costs accounted for the largest share of health care costs, followed by inpatient, pharmacy, and emergency department service costs. This pattern differs from previous reports of TRD in commercially insured populations in which pharmacy and inpatient costs accounted for a proportionately larger share of costs than outpatient care costs. ${ }^{8,17}$ Although further analyses are needed to probe the basis of these patterns, it is possible that the high background prevalence of persistent serious health conditions in the Medicaid sample ${ }^{31}$ contributes to the proportionately greater contribution of outpatient care to their cost profile ${ }^{32}$ and that Medicaid formulary restrictions designed to restrict access to specified high-cost medications contributes to their relatively lower pharmacy costs.

Inpatient care costs were substantially higher among patients with TRD than among patients without TRD. Most of these costs were not directly related to claims-based diagnoses of depression or other mental health conditions. Prospective research strongly suggests bidirectional etiologic relationships between depression and several common general medical conditions, including diabetes mellitus, ${ }^{31}$ ischemic heart disease, ${ }^{32}$ and chronic pulmonary disease. ${ }^{33}$ Because depression tends to decrease adherence to a wide range of medication treatment regimens,${ }^{34}$ persistent depression can also adversely affect the clinical course of general medical conditions. Improving the management of depression, especially TRD, may offer opportunities to capture cost-offsets associated with integrated mental health and general medical care. ${ }^{35}$

Little is known about the clinical course of TRD. Previous claims-based studies have focused on 1-year periods or episode 
lengths defined by the pattern of depression treatment. ${ }^{6,7,8,11,17}$ We found that differences between depressed patients with TRD and those without TRD in health care costs and services, including depression-related outpatient and inpatient services, persisted during the first year following the year in which TRD developed. A clinical implication of these enduring service demands of TRD patients is that they may commonly require longer-term depression treatment. Although the American Psychiatric Association's practice guideline for MDD recommends that in order to reduce the risk of relapse, patients who have been successfully treated with antidepressants should be continued for 4-9 months beyond the acute phase of treatment, ${ }^{22}$ longer episodes of maintenance depression treatment may be indicated for patients with TRD.

The clinical literature suggests that TRD runs a variable course, with many patients having enduring depressive symptoms. ${ }^{36-38}$ In a study of patients with moderately advanced unipolar or bipolar TRD, only $7.8 \%$ of patients reported symptomatic remission during the week preceding their 2-year follow-up assessment. ${ }^{36}$ Another study that followed adults with treatment-resistant unipolar or bipolar depression for an average of 3 years found that patients experienced depressive symptoms during nearly two thirds (61\%) of the follow-up months. ${ }^{37} \mathrm{~A}$ third long-term follow-up study reported that approximately half (48\%) of patients with persistent affective disorders achieved symptomatic remission for the 6-month period preceding their 5 -year assessments. ${ }^{38}$ The frequent persistent nature of depressive symptoms in patients with TRD likely contributes to their long-term health care costs.

\section{Limitations}

This study has several potential limitations. First, diagnoses were based on clinical judgments of treating clinicians and were not subject to expert validation through structured assessments. Depression and other mental disorders may be underreported in claims data because of social stigma and financial incentives to bill for the management of general medical disorders, although we have no reason to believe that underreporting operated differentially across study groups.

Second, a lack of clinical measures for depressive symptoms in the claims database prevents direct assessment of treatment response and resistance. Without prospective clinical data, it is also not possible to distinguish switches in treatments for MDD that were related to treatment nonadherence, ineffectiveness, and intolerability. However, our overall rate of TRD (25.9\%) is similar to the rate reported from a large clinical sample of depressed patients who remained depressed after 2 treatment trials $(21.9 \%){ }^{39}$
Third, the analyses were limited to nonelderly adult Medicaid patients without Medicare coverage, so the results may not generalize to older patients, those with dual eligibility, or other patient populations. Fourth, the cost estimates were not adjusted for inflation.

Fifth, diagnoses within claims data do not permit precise attribution of mental health-related and depression-related service costs. For example, even subthreshold depressive symptoms have been associated with increased medical care costs of adults with diabetes..$^{40}$ Finally, it is not known whether the persistence of increased service use and health care costs observed during the second year would continue over longer periods of observation.

\section{Conclusions}

Within the U.S. Medicaid program, patients with MDD who have evidence of TRD have substantially higher health care costs than their counterparts who do not meet criteria for TRD. This general finding may be particularly important to thirdparty payers and managers of health care benefits who bear financial responsibility for health care costs or oversee service delivery to this patient population. The persistence of health care cost differences over the year following development of TRD suggests that depression treatment resistance is often an enduring clinical characteristic. In addition to demonstrating the practical utility of retrospective Medicaid claims to identify patterns and costs associated with treatment resistance, these results underscore the challenge of developing interventions and management strategies to meet the complex and enduring clinical needs of this large and vulnerable patient population.

\section{Authors}

MARK OLFSON, MD, MPH, Department of Psychiatry, College of Physicians and Surgeons, Columbia University and New York State Psychiatric Institute, New York, New York. TONY B. AMOS, PharmD, MS; CARMELA BENSON, MS; and JACQUELYN MCRAE, PharmD, Health Economics and Outcomes Research, Janssen Scientific Affairs, Titusville, New Jersey. STEVEN C. MARCUS, PhD, School of Social Practice E Policy, University of Pennsylvania, Philadelphia.

AUTHOR CORRESPONDENCE: Mark Olfson, MD, MPH, New York State Psychiatric Institute/Department of Psychiatry, College of Physicians and Surgeons of Columbia University, 1051 Riverside Dr., New York, NY 10032. Tel.: 646-774-6413; E-mail:mo49@cumc.columbia.edu. 


\section{DISCLOSURES}

This project was sponsored by Janssen Scientific Affairs. Olfson received a grant from Janssen Scientific Affairs through Columbia University Medical Center. Amos and Benson are employees of Janssen Scientific Affairs. Marcus was paid by Janssen Scientific Affairs to provide consulting support for this study and reports fees from Sunovion Pharmaceuticals and Alkermes outside of this study. McRae was a fellow affiliated with Janssen Scientific Affairs during the development of this research and manuscript.

Study concept and design were contributed by Amos, Olfson, Marcus, Benson, and McRae. Data analysis was performed by all the authors. The manuscript was primarily written by Olfson, along with the other authors, and revised by McRae, Benson, Amos, Marcus, and Olfson.

A different data cut from the same database was presented previously at the 2017 Annual Meeting of the International Society for Pharmacoeconomics and Outcomes Research; May 20-24, 2017; Boston, MA; and the 2017 AcademyHealth Annual Research Meeting; June 25-27, 2017; New Orleans, LA.

\section{ACKNOWLEDGMENTS}

Editorial support was provided by Wilson Joe, $\mathrm{PhD}$, of MedErgy, and sponsored by Janssen Scientific Affairs.

\section{REFERENCES}

1. Hasin DS, Goodwin RD, Stinson FS, Grant BF. Epidemiology of major depressive disorder: results from the National Epidemiologic Survey on Alcoholism and Related Conditions. Arch Gen Psychiatry. 2005;62(10):1097-106.

2. Eaton WW, Martins SS, Nestadt G, Bienvenu OJ, Clarke D, Alexandre P. The burden of mental disorders. Epidemiol Rev. 2008;30:1-14.

3. Greenberg PE, Fournier AA, Sisitsky T, Pike CT, Kessler RC. The economic burden of adults with major depressive disorder in the United States (2005 and 2010). J Clin Psychiatry. 2015;76(2):155-62.

4. Trivedi MH, Rush AJ, Wisniewski SR, et al. Evaluation of outcomes with citalopram for depression using measurement-based care in STAR*D: implications for clinical practice. Am J Psychiatry. 2006;163(1):28-40.

5. Ruhe HG, van Rooijen G, Spijker J, Peeters FP, Schene AH. Staging methods for treatment resistant depression. A systematic review. J Affect Disord. 2012;137(1-3):35-45.

6. Corey-Lisle PK, Birnbaum HG, Greenberg PE, Marynchenko MB, Claxton AJ. Identification of a claims data "signature" and economic consequences for treatment-resistant depression. J Clin Psychiatry. 2002;63(8):717-26.

7. Gibson TB, Jing Y, Smith Carls G, et al. Cost burden of treatment resistance in patients with depression. Am J Manag Care. 2010;16(5):370-77.

8. Kubitz N, Mehra M, Potluri RC, Garg N, Cossrow N. Characterization of treatment resistant depression episodes in a cohort of patients from a U.S. commercial claims database. PLoS One. 2013;8(10):e76882.

9. Souery D, Amsterdam J, de Montigny C, et al. Treatment resistant depression: methodological overview and operational criteria. Eur Neuropsychopharmacol. 1999;9(1-2):83-91.

10. Rizvi SJ, Grima E, Tan M, et al. Treatment-resistant depression in primary care across Canada. Can J Psychiatry. 2014;59(7):349-57.

11. Russell JM, Hawkins K, Ozminkowski RJ, et al. The cost consequences of treatment-resistant depression. J Clin Psychiatry. 2004;65(3):341-47.

12. Mrazek DA, Hornberger JC, Altar CA, Degtiar I. A review of the clinical, economic, and societal burden of treatment-resistant depression: 1996-2013. Psychiatr Serv. 2014;65(8):977-87.

13. Crown WH, Finkelstein S, Berndt ER, et al. The impact of treatmentresistant depression on health care utilization and costs. J Clin Psychiatry. 2002;63(11):963-71.

14. Conway CR, Gebara MA, Walker MC, et al. Clinical characteristics and management of treatment-resistant depression. J Clin Psychiatry. 2015:76(11):1569-70
15. Olchanski N, McInnis Myers M, Halseth M, et al. The economic burden of treatment-resistant depression. Clin Ther. 2013;35(4):512-22.

16. Ivanova JI, Birnbaum HG, Kidolezi Y, Subramanian G, Khan SA, Stensland MD. Direct and indirect costs of employees with treatment-resistant and non-treatment-resistant major depressive disorder. Curr Med Res Opin. 2010;26(10):2475-84

17. Greenberg P, Corey-Lisle PK, Birnbaum H, Marynchenko M, Claxton A Economic implications of treatment-resistant depression among employees Pharmacoeconomics. 2004;22(6):363-73.

18. Rush AJ, Trivedi MH, Wisniewski SR, et al. Bupropion-SR, sertraline, or venlafaxine-XR after failure of SSRIs for depression. N Engl J Med. 2006;354(12):1231-42.

19. Garfield RL. Mental health financing in the United States: a primer The Kaiser Commission on Medicaid and the Uninsured. April 2011. Available at: https://kaiserfamilyfoundation.files.wordpress. com/2013/01/8182.pdf. Accessed February 9, 2018

20. de Sousa RT, Zanetti MV, Brunoni AR, Machado-Vieira R. Challenging treatment-resistant major depressive disorder: a roadmap for improved therapeutics. Curr Neuropharmacol. 2015;13(5):616-35.

21. Chandler GM, Iosifescu DV, Pollack MH, Targum SD, Fava M. RESEARCH: Validation of the Massachusetts General Hospital Antidepressant Treatment History Questionnaire (ATRQ). CNS Neurosci Ther. 2010;16(5):322-25.

22. American Psychiatric Association. Practice guidelines for treatment of patients with major depressive disorder, 3rd ed. October 2010. Available at: https://psychiatryonline.org/pb/assets/raw/sitewide/practice_guidelines/ guidelines/mdd.pdf. Accessed February 9, 2018.

23. Elixhauser A, Steiner C, Harris DR, Coffey RM. Comorbidity measures for use with administrative data. Med Care. 1998;36(1):8-27.

24. Belotti F, Deb P, Manning WG, Norton EC. twopm: two-part models. Stata J. 2015;15:3-20.

25. Mullahy J. Much ado about two: reconsidering retransformation and the two-part model in health econometrics. J Health Econ. 1998;17(3):247-81.

26. Craighead WE, Dunlop BW. Combination psychotherapy and antidepressant medication treatment for depression: for whom, when, and how. Annu Rev Psychol. 2014:65:267-300.

27. Fournier JC, DeRubeis RJ, Shelton RC, Hollon SD, Amsterdam JD, Gallop R. Prediction of response to medication and cognitive therapy in the treatment of moderate to severe depression. J Consult Clin Psychol. 2009;77(4):775-87.

28. Olfson M, Blanco C, Marcus SC. Treatment of adult depression in the United States. JAMA Intern Med. 2016;176(10):1482-91

29. Mechanic D, Olfson M. The relevance of the Affordable Care Act for improving mental health care. Annu Rev Clin Psychol. 2016;12:515-42.

30. Katon WJ, Lin EH, Von Korff M, et al. Collaborative care for patients with depression and chronic illnesses. N Engl J Med. 2010;363(27):2611-20.

31. Pan A, Lucas M, Sun Q, et al. Bidirectional association between depression and type 2 diabetes mellitus in women. Arch Intern Med. 2010;170(21):1884-91.

32. Khawaja IS, Westermeyer JJ, Gajwani P, Feinstein RE. Depression and coronary artery disease: the association, mechanisms, and therapeutic implications. Psychiatry (Edgmont). 2009;6(1):38-51.

33. Atlantis E, Fahey P, Cochrane B, Smith S. Bidirectional associations between clinically relevant depression or anxiety and COPD: a systematic review and meta-analysis. Chest. 2013;144(3):766-77.

34. DiMatteo MR, Lepper HS, Croghan TW. Depression is a risk factor for noncompliance with medical treatment: meta-analysis of the effects of anxiety and depression on patient adherence. Arch Intern Med. 2000;160(14):2101-07. 
35. Blount A, Schoenbaum M, Kathol R, Rollman BL. The economics of behavioral health services in medical settings: a summary of the evidence. Prof Psychol Res Pr. 2007;38(3):390-97.

36. Dunner DL, Rush AJ, Russell JM, et al. Prospective, long-term, multicenter study of the naturalistic outcomes of patients with treatment-resistant depression. J Clin Psychiatry. 2006;67(5):688-95.

37. Vergunst FK, Fekadu A, Wooderson SC, et al. Longitudinal course of symptom severity and fluctuation in patients with treatment-resistant unipolar and bipolar depression. Psychiatry Res. 2013;207(3):143-49.
38. Coryell W, Endicott J, Keller M. Outcome of patients with chronic affective disorder: a five-year follow-up. Am J Psychiatry. 1990;147(12):1627-33.

39. Perlis RH. A clinical risk stratification tool for predicting treatment resistance in major depressive disorder. Biol Psychiatry. 2013;74(1):7-14.

40. Ciechanowski PS, Katon WJ, Russo JE. Depression and diabetes: impact of depressive symptoms on adherence, function, and costs. Arch Intern Med. 2000;160(21):3278-85. 


\section{APPENDIX A Sample Selection}

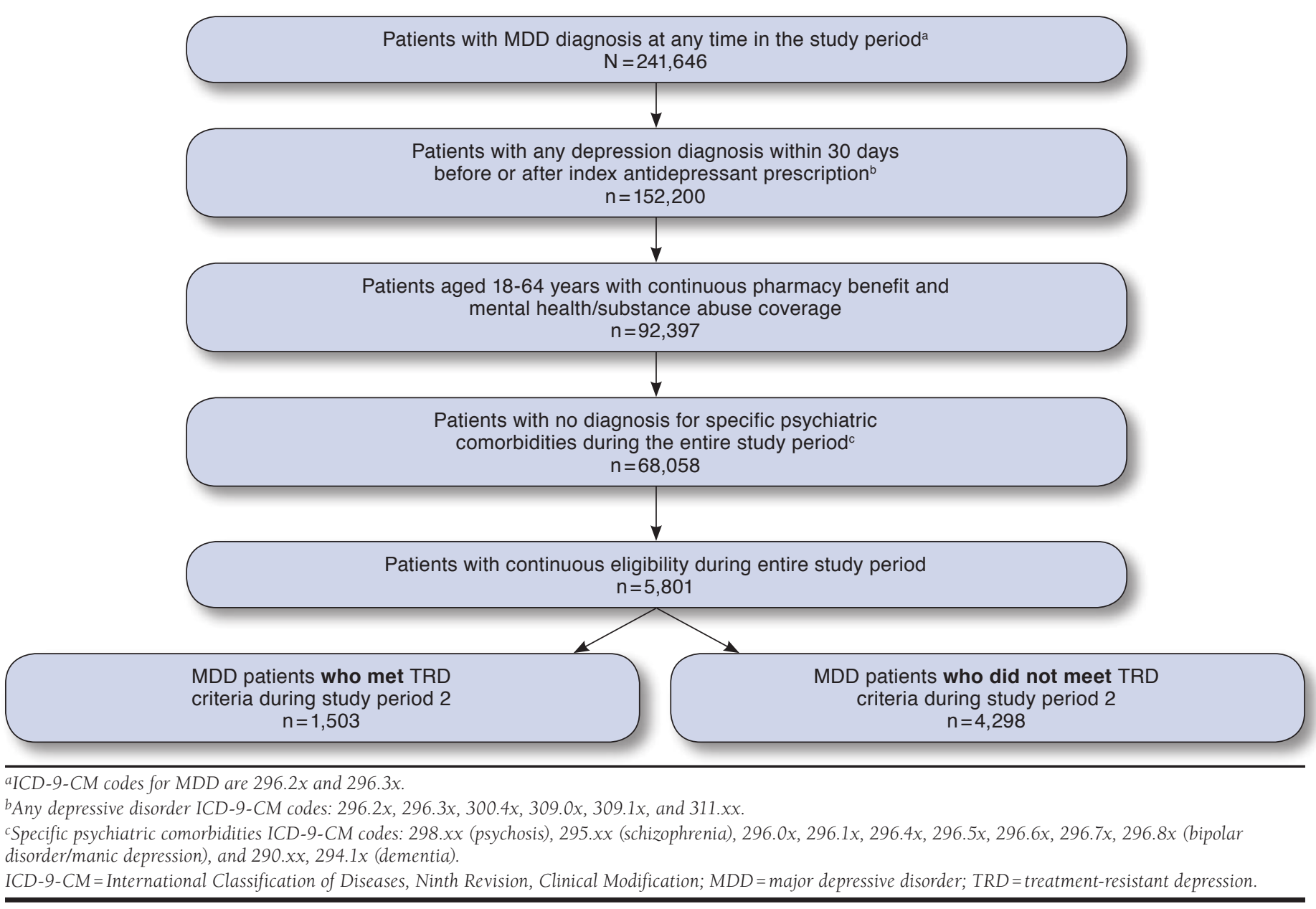




\section{APPENDIX B List of Antidepressant Medications, Minimum Adequate Doses, and Augmentation Medications}

\begin{tabular}{|c|c|c|}
\hline Antidepressant Medication & $\begin{array}{l}\text { Minimum Daily } \\
\text { Adequate Dose }^{\mathrm{a}}\end{array}$ & Augmentation Medications \\
\hline SSRIs & & Anticonvulsant medication \\
\hline Citalopram & $20 \mathrm{mg}$ & Carbamazepine \\
\hline Escitalopram & $10 \mathrm{mg}$ & Gabapentin \\
\hline Fluoxetine & $20 \mathrm{mg}$ & Lamotrigine \\
\hline Paroxetine & $20 \mathrm{mg}$ & Phenytoin \\
\hline Paroxetine, extended release & $12.5 \mathrm{mg}$ & Tiagabine \\
\hline Sertraline & $50 \mathrm{mg}$ & Topiramate \\
\hline Vilazodone & $10 \mathrm{mg}$ & Anxiolytic medication \\
\hline DNRI & & Buspirone \\
\hline Bupropion & $150 \mathrm{mg}$ & Antipsychotic medication \\
\hline SNRIs & & Aripiprazole \\
\hline Desvenlafaxine & $50 \mathrm{mg}$ & Olanzapine \\
\hline Duloxetine & $60 \mathrm{mg}$ & Paliperidone \\
\hline Levomilnacipran & $20 \mathrm{mg}$ & Quetiapine \\
\hline Milnacipran & $12.5 \mathrm{mg}$ & Risperidone \\
\hline Venlafaxine & $37.5 \mathrm{mg}$ & Ziprasidone \\
\hline Serotonin modulators & & Lithium medication \\
\hline Nefazodone & $50 \mathrm{mg}$ & Lithium \\
\hline Trazodone & $150 \mathrm{mg}$ & Psychostimulant \\
\hline Vortioxetine & $10 \mathrm{mg}$ & Dextroamphetamine \\
\hline Norepinephrine-serotonin modulator & & Methamphetamine \\
\hline Mirtazapine & $15 \mathrm{mg}$ & Methylphenidate \\
\hline Tricyclic and tetracyclic antidepressants & & Modafinil \\
\hline Amitriptyline & $25 \mathrm{mg}$ & Pemoline \\
\hline Amoxapine & $25 \mathrm{mg}$ & Thyroid hormone medication \\
\hline Doxepin & $25 \mathrm{mg}$ & Liothyronine \\
\hline Desipramine & $25 \mathrm{mg}$ & \\
\hline Imipramine & $25 \mathrm{mg}$ & \\
\hline Maprotiline & $75 \mathrm{mg}$ & \\
\hline Nortriptyline & $25 \mathrm{mg}$ & \\
\hline Protriptyline & $10 \mathrm{mg}$ & \\
\hline Trimipramine & $25 \mathrm{mg}$ & \\
\hline \multicolumn{3}{|l|}{ MAOIs } \\
\hline Isocarboxazid & $10 \mathrm{mg}$ & \\
\hline Moclobemide & $150 \mathrm{mg}$ & \\
\hline Phenelzine & $15 \mathrm{mg}$ & \\
\hline Selegiline transdermal & $6 \mathrm{mg}$ & \\
\hline Tranylcypromine & $10 \mathrm{mg}$ & \\
\hline \multicolumn{3}{|l|}{ Other selected medication } \\
\hline Olanzapine-fluoxetine & $25 \mathrm{mg}$ & \\
\hline
\end{tabular}

